\title{
Comparative Analysis of Stability-Genetic Diversity in Seagrass (Posidonia oceanica) Meadows Yields Unexpected Results
}

\author{
Sophie Arnaud-Haond ${ }^{1,2,{ }^{*}}$, Núria Marbà ${ }^{3}$, Elena Diaz-Almela ${ }^{3}$, Ester A. Serrão ${ }^{1}$ and Carlos M. Duarte ${ }^{3}$ \\ ${ }^{1}$ Laboratory MAREE CCMAR, CIMAR_Laboratório Associado, Univ. Algarve, Gambelas, 8005-139 Faro, \\ Portugal \\ 2 IFREMER, Laboratoire Environnement Profond-Centre de Brest, BP70, 29280 Plouzané, France \\ ${ }^{3}$ Department of Global Change Research, IMEDEA (CSIC-UIB), C/ Miquel Marques 21, 07190 Esporles, \\ Mallorca, Spain \\ *: Corresponding author : Sophie Arnaud-Haond, email address : sarnaud@ifremer.fr
}

\begin{abstract}
:
The diversity-stability relationship is the subject of a long-standing debate in ecology, but the genetic component of diversity has seldom been explored. In this study, we analyzed the interplay between genetic diversity and demographic responses to environmental pressures. This analysis included 30 meadows formed by the Mediterranean endemic seagrass, Posidonia oceanica, showing a wide range of population dynamics ranging from a near equilibrium state to steep decline due to strong environmental pressures close to aquaculture installations. Our results show that sedimentation rates are much better predictors of mortality than clonal or genetic components. An unexpected positive trend was observed between genotypic diversity and mortality, along with a negative relationship between allelic richness and net population growth. Yet such trends disappeared when excluding the most extreme cases of disturbance and mortality, suggesting the occurrence of a threshold below which no relationship exists. These results contrast with the positive relationship between genotypic diversity and resistance or resilience observed in previous manipulative experiments on seagrass. We discuss the reasons for this discrepancy, including the difficulties in designing experiments reflecting the complexity of natural meadows.
\end{abstract}

Keywords: Seagrass - Demography - Clonality - Genetic richness - Diversity-stability - Posidonia oceanica 
The relationship between diversity and stability has been the subject of a long-standing debate in ecology. Many components of diversity have been tested for their effect on resistance or resilience to environmental perturbations, at levels ranging from populations to ecosystems. Among other components of diversity, clonal diversity, taxa diversity (mainly from species to genera) and functional diversity have been investigated (Naeem \& Li 1997, McCann 2000). Depending on the study and the proxies measured, various trends or lack of trends have been observed (J ohnson et al. 1996, Loreau et al. 2001, Pfisterer $\&$ Schmid 2002, Worm et al. 2006).

The genetic component of biodiversity has so far been largely neglected in such observational and experimental studies. At best, some authors working on resistance and resilience of clonal organisms to environmental pressures have experimentally tested the effect of genotypic diversity (Hughes \& Stachowicz 2004, Reusch et al. 2005), which reflects the number of clonal lineages (roughly the number of genetic individuals arising from distinct events of clonal reproduction) but does not necessarily correlate with genetic diversity (Hughes \& Stachowicz 2004, Hughes et al. 2008). Nevertheless, the existence of effects of genetic diversity on the potential of populations and species to overcome environmental fluctuations is a strong underlying assumption driving most interpretations and conclusions in molecular ecology in general and in conservation genetics in particular (Frankham 1995, Spielman et al. 2004, Frankham 2005).

It is widely assumed that genetic impoverishment affects the resistance and resilience of populations and species against future environmental changes, thereby potentially threatening their mid-term survival. This expectation results from two complementary effects. First, the loss of polymorphism would lower the 'evolutionary potential' of populations (Frankel 1974), the capacity to adapt to a range of variable environmental conditions. Second, loss of polymorphism below a certain threshold would increase the likelihood of inbreeding with deleterious effects (Frankel \& Soule 1981) and of accumulation of deleterious mutations (Lande 1995, Lynch et al. 1995). Both the overall consequences of the loss of diversity and the effects of inbreeding alone have been demonstrated empirically for the 
demography of several species (Newman \& Pilson 1997, Saccheri et al. 1998, Spielman et al. 2004).

In contrast, there is still little evidence for the theoretically expected negative effect of the loss of 'evolutionary potential' and the nature of the hypothetical relationship between genetic diversity and

81 population vulnerability.

A well-established trend, both theoretically (Kimura 1983) and empirically (Spielman et al. 2004), is that large populations with positive demographic balance sustain higher genetic diversity than small declining populations. What remains to be empirically demonstrated is, apart from inbreeding, whether higher diversity in terms of allelic variants may in turn provide populations with a greater likelihood of adapting to a wide range of environmental conditions, thereby positively influencing their demography. A positive relationship between demography and genetic diversity may be expected for both reasons, preventing the assessment of whether demography drives genetic diversity or vice versa. The possible circular nature of the arguments challenges efforts to dissociate the respective influence of these two putative drivers, demographic and genetic status, on the basis of empirical relationships between demographic status and genetic diversity in natural populations. However, in long-living (longevity of centuries or millennia), slow-growing organisms, these relationships cannot be tested by assessing the demographic performance of experimental populations across a gradient of genetic diversity, because the duration of the experiments would span across several human generations. Conversely, the effect of genetic diversity on demographic responses to environmental pressures could be examined across a range of populations for which genetic diversity prior to disturbance was known, but such pre-disturbance information is largely lacking.

Seagrass meadows are highly valuable marine habitats experiencing a worldwide decline at rates of about 1 to $3 \%$ per year due to the combination of a number of pressures leading to increasing

102 anthropogenic pressure on coastal areas (Orth et al. 2006). Meadows formed by the Mediterranean 103 species Posidonia oceanica, a long-lived, highly clonal species (Arnaud-Haond et al. 2007b), are declining at a rate of about $5 \%$ per year (Marbà et al. 2005). Testing for a possible role of genetic

105 diversity in the resistance of Posidonia oceanica meadows to environmental pressures is an important goal in order to infer which meadows may be more vulnerable to these pressures. Preliminary 
107 transplant experiments have provided some evidence indicating that genetic diversity enhances

108 survival of transplants ( $P$. oceanica: Procaccini \& Piazzi 2001), but lower mortality rates have been reported in Posidonia oceanica meadows subjected to aquaculture impacts where genotypic and

110 genetic diversity were lower (Diaz-Almela et al. 2007). Hence, the role of genetic diversity in the 111 response of Posidonia oceanica meadows to disturbance remains unclear.

112

113 Coastal eutrophication is the major cause of seagrass decline worldwide (Orth et al 2006). Excessive

114 inputs of organic matter and nutrients to coastal areas fuel sediment microbial activity, increasing the 115 production of sulfide (e.g. Holmer et al 2008; Mascaró et al 2009) and ammonium (e.g. Frederiksen et 116 al 2008) and causing sediment anoxia. Eutrophication may also reduce light availability to seagrass 117 meadows (due to the proliferation of phytoplankton and macroalgae) and increase grazing pressure. 118 All of these processes are detrimental to seagrass survival and growth. Benthic sedimentary inputs of 119 organic matter and particulate nutrients to $P$. oceanica meadows have been demonstrated to be a 120 useful proxy for coastal eutrophication, particularly when deterioration of the water column is not 121 evident, as is often the case in Mediterranean coastal areas (Díaz-Almela et al 2008). Although 122 seagrasses are often nutrient limited, and their productivity could thus increase with coastal nutrient 123 enrichment, it has been demonstrated that organic and nutrient loading to $P$. oceanica sediments 124 triggers plant mortality and meadow decline when it exceeds $1.5 \mathrm{gDW}$ organic matter $\mathrm{m}^{-2}$ day $^{-1}, 50$ $125 \mathrm{mg} \mathrm{P} \mathrm{m}^{-2}$ day $^{-1}$ or $40 \mathrm{mg} \mathrm{N} \mathrm{m}^{-2}$ day $^{-1}$ (Díaz-Almela et al 2008).

Here, we test the prediction that genetic diversity plays a role in the resistance of Posidonia 128 oceanica to environmental pressures, particularly inputs of organic matter and nutrients (nitrogen and 129 phosphorous) to the sediments. We first examine the genetic diversity of $30 P$. oceanica meadows across the Mediterranean Sea in order to test for the existence of a possible relationship between the 131 demographic dynamics and the genotypic (i.e., clonal) and genetic (allelic) composition of the 132 meadows. We then assess, for 14 meadows receiving different amounts of organic and nutrient 133 benthic inputs, whether genetic diversity affects the relationship between $P$. oceanica demography 134 and environmental pressures (i.e., inputs of organic matter and particulate nitrogen and 135 phosphorous). 
139 A total of 30 P. oceanica populations spanning the Mediterranean basin from Spain to Cyprus were 140 sampled from summer 2001 to summer 2003. About 40 shoots were collected at randomly selected 141 coordinates within a 1600- $\mathrm{m}^{2}(80 \times 20 \mathrm{~m})$ area at each site (Arnaud-Haond et al. 2007b, Diaz-Almela 142 et al. 2007). The basal, meristematic section of the leaves was removed and preserved in silica 143 crystals for later analysis. Twelve of these populations were analyzed in a previous study on 144 biogeography (Arnaud-Haond et al. 2007b); eight were sampled in the context of a study on the 145 effects of aquaculture installations on P. oceanica meadows (Diaz-Almela et al. 2007, Holmer et al. 146 2008); and ten others were newly added for this study (Table 1).

149 Genomic DNA was isolated using a CTAB extraction procedure (Doyle \& Doyle 1987). All meadows

150 were analyzed with the most efficient combination (Arnaud-Haond et al. 2005) of seven dinucleotide 151 microsatellite markers (Alberto et al. 2003), as described in Arnaud-Haond et al. (2007b).

152

Details of the methods used for clone (genet) discrimination

154 When the same genotype was detected more than once, the probability that the samples actually

155 originated from distinct reproductive events (i.e., from separate genets) was estimated (Tibayrenc et 156 al. 1990, Parks \& Werth 1993), taking into account Wright's inbreeding coefficient estimated for each 157 locus (Young et al. 2002). The procedure was based on the round-robin method (Parks \& Werth 1993) 158 to estimate the allelic frequencies at nuclear loci in each population.

159

$$
p_{\text {gen(fis) }}=\prod_{\mathrm{i}=1}^{1}\left[\left(\mathrm{f}_{\mathrm{i}} \mathrm{g}_{\mathrm{i}}\right) *\left(1+\left(\mathrm{z}_{\mathrm{i}} \times\left(F_{\mathrm{is}(\mathrm{i})}\right)\right)\right)\right] 2^{\mathrm{h}}
$$


160 where $\mathrm{I}$ is the number of loci, $\mathrm{h}$ is the number of heterozygous loci, and $\mathrm{f}$ and $\mathrm{g}$ are the allelic

161 frequencies of the alleles $f$ and $g$ at the $i^{\text {th }}$ locus ( $f$ and $g$ are identical for homozygotes; $F_{\text {is }(i)}$ is the $F_{\text {is }}$

162 estimated for the $\mathrm{i}^{\text {th }}$ locus using the round-robin method; and $\mathrm{z}_{\mathrm{i}}=1$ for the $\mathrm{i}^{\text {th }}$ locus if it is homozygous

163 and -1 for the $i^{\text {th }}$ locus if it is heterozygous).

164 When the same genotype is detected more than once $(n)$ in a population sample composed of $\mathrm{N}$

165 ramets, the probability that these sample units actually originate from distinct reproductive events

166 (i.e., from separate genets) is described by the binomial expression (Tibayrenc et al. 1990, Parks \&

167 Werth 1993):

168

$\left.p_{\text {sex(fis) }}=\sum_{\mathrm{i}=\mathrm{n}}^{\mathrm{N}} \frac{\mathrm{N} !}{\mathrm{i} !(\mathrm{N}-\mathrm{i}) !}\left[p_{\text {gen(fis) }}\right]^{\mathrm{i}}\left[1-p_{\text {gen(fis) }}\right)\right]^{\mathrm{N}-\mathrm{i}}$

169 where $\mathrm{n}$ is the number of sampled ramets with the same multilocus genotype, $\mathrm{N}$ is the sample size,

170 and $p_{\text {gen(fis) }}$ is the probability of the common genotype.

171 The possible occurrence of somatic mutations or scoring errors resulting in slightly distinct Multi-Locus

172 Genotypes (MLG) actually derived from a single reproductive event, and therefore belonging to a single

173 clone, was tested for. When significant results were obtained, Multi-Locus Lineages (MLL) were then

174 defined, including the slightly distinct MLGS (Arnaud-Haond et al. 2007a, Arnaud-Haond et al. 2007b).

175 All calculations were performed using the software GenClone2.1 (Arnaud-Haond \& Belkhir 2007).

Genotypic diversity estimates

177 Genotypic richness was estimated from the number of ramets sampled (N) and the number of

178 multilocus genotypes detected (G), as suggested by Dorken et al. (2002):

$179 \quad R=\frac{(G-1)}{(N-1)}$

180 The Pareto distribution, which describes the skewed distribution of genotypes among lineages in

181 clonal organisms (Arnaud-Haond et al. 2007a, Arnaud-Haond et al. 2007b), was estimated for each

182 meadow. The parameters of that distribution, beta (derived from the slope) and the maximum MLL 

size (in terms of number of replicates), were used as indicators of the evenness and diversity of each meadow, as proposed in Arnaud-Haond et al (2007a) and implemented in Genclone 2.1 (ArnaudHaond \& Belkhir 2007).

186 The clonal subrange (Harada et al. 1997), an estimate of the maximal extent of clones, was also 187 estimated for each population using Genclone 2.1 (Arnaud-Haond \& Belkhir 2007).

188

Genetic diversity estimates

Allelic richness was estimated after randomly subsampling each sample to standardize it to the maximum common sample size between populations after removing clonal replicates (Arnaud-Haond

$192 \&$ Belkhir 2007, Arnaud-Haond et al. 2007a).

193 Expected heterozygosity was estimated on the set of multilocus lineages defined after removing ramets derived from the same zygote ancestor according to $\mathrm{p}_{\text {sex(fis), }}$, using Genetix (Belkhir et al. 1996195 2001).

We assessed the demography of the seagrass (Posidonia oceanica) using repeated annual censuses of marked shoots in the same 30 meadows where genetic and genotypic diversity was assessed, from Cyprus to Spain. Seagrass demography at all Spanish meadows except El Campello was estimated from 2000 to 2002 (Marbà et al 2005). Seagrass demography was quantified at Cyprus, Italy and El

202 Campello (Spain) from 2002 to 2003 and for Greece between 2003 and 2004 (Díaz-Almela et al.

203 2008). In fourteen meadows, the level of disturbance, as represented by inputs of organic matter and 204 particulate nutrients to the sediments, was measured. The meadows ranged in conservation status 205 from protected, relatively pristine areas to highly disturbed sites located in the vicinity of fish farms 206 that delivered important loads of organic matter and nutrients to the sediments (Diaz-Almela et al. 207 2007, Holmer et al. 2008). At each meadow, we installed three permanent plots at the bottom by 208 SCUBA diving, using metal sticks, ropes and buoys, as explained in detail in Marbà et al. (2005). The 209 size of the triplicate quadrats was adjusted to encompass at least 100 shoots per quadrat. We performed two direct censuses of the shoots present within the permanent plots at each site. 
211 Censuses were separated by about one year (from 307 to 386 days). During the first census, all

212 shoots within each plot were counted and marked by placing a plastic cable tie around the rhizomes.

213 During the second census, the number of surviving shoots (identified as those marked in the previous

214 census) and the number of recruited ones (identified as young unmarked shoots) were counted. We

215 calibrated the counting error by having two plots counted by independent observers, yielding an

216 estimated error of $\pm 0.2 \%$ and $\pm 3.5 \%$ of the total shoot population for recruits and lost shoots,

217 respectively.

218

219 The repeated censuses allowed direct estimates of specific rates $\left(y r^{-1}\right)$ of shoot mortality, recruitment

220 and net population growth rate (Marbà et al. 2005).

221 The specific shoot mortality rate $\left(R M R\right.$, in year $\left.{ }^{-1}, y r^{-1}\right)$ was estimated, assuming an exponential

222 population growth model, as

223

$224 \quad \mathbf{R M R}=-\frac{\left(\ln N_{S 1} / N_{t 0}\right) \times 365}{t_{1}-t_{0}}$

226 where $N_{t 0}$ is the total number of shoots (vertical and horizontal apices) counted in the initial census

227 ( $t_{0}$, days) at each plot and $N_{S 1}$ is the total number of surviving shoots at the second census ( $t_{1}$, days).

228 The specific shoot recruitment rate $\left(R R R\right.$, in $\left.y r^{-1}\right)$ was estimated, assuming an exponential population 229 growth model, as

230

$231 \quad \mathbf{R R R}=\frac{\ln \left(\left(N_{r 1}+N_{s 1}\right) / N_{s 1}\right) \times 365}{t_{1}-t_{0}}$

233 where $N_{r 1}$ is the total number of recruited shoots observed at $t_{1}$ and $N_{s 1}$ is the number of survivors at $234 t_{1}$

235 Specific net population growth rates (NPG, in $y r^{-1}$ ) were estimated as

236 
$237 N P G=\mathbf{R R R}-R \mathbf{M R}=\frac{\ln \left(N_{t 1} / N_{t 0}\right)}{t_{1}-t_{0}} \times 365$

238 Where $N_{t 1}$ is the total number of shoots present at $t_{1}$.

239

Sedimentation rates

241 We measured sedimentation rates at each station by deploying benthic sediment traps next to the 242 plots for periods of about $48 \mathrm{~h}$. The sediment traps were designed after Gacia et al. (1999) and 243 consisted of two replicated arrays situated $20 \mathrm{~cm}$ above the bottom, each supporting five 20-ml 244 cylindrical glass centrifugation tubes with an aspect ratio of 5 (16 $\mathrm{mm}$ diameter), in order to minimize 245 internal re-suspension. The contents of 1-3 tubes were combined and collected on a combusted, pre246 weighed Whatman GF/F filter. Dry weight of total sediment deposition was obtained after drying the 247 filters at $60^{\circ} \mathrm{C}$ to constant weight. Dry weight of organic matter (OM) deposition was measured 248 through combustion of some of the filters. Total P (TP) was obtained after boiling combusted 249 materials in $1 \mathrm{M} \mathrm{HCl}$ for 15 min followed by spectrophotometric determination of phosphate (Koroleff 250 1983). We analyzed the un-combusted samples for total N content with an elemental analyzer (Iso251 Analytical Ltd., United Kingdom). Further information on these analyses and spatial patterns of fish252 farm inputs are shown in Holmer et al. (2008). We estimated total matter, organic matter, N and P 253 sedimentation rates from these measurements according to Blomqvist and Håkanson (1981) and 254 Hargrave and Burns (1979), as described in detail in Gacia et al. (1999).

255

256 Using least squares linear regression analysis, we examined the overall relationship between 257 genotypic diversity (R, Pareto beta and maximum MLL size) or genetic diversity (allelic richness, 258 unbiased heterozygosity) and seagrass demography (specific mortality, specific recruitment, specific 259 net population growth) as well as relationships between shoot mortality or net rate of population 260 change and sedimentation rates. We also tested the relationships between the residuals of these 261 regressions and genotypic and genetic diversity to examine whether high genotypic and genetic 262 diversity lead to lower mortality and/or a higher net rate of population growth for a given degree of 263 environmental pressure. 
264 Because net population growth (NPG) is dependent on both the mortality (RMR) and recruitment

265 (RRR; NPG=RRR-RMR) rates, the correlation obtained for NPG may not be independent from those for 266 RMR and RRR. Depending on which of the two factors is the predominant force driving the

267 demography of the meadow, the correlation observed for NPG may be negatively related to those

268 obtained for M or positively related to those obtained for RRR.

269 Because multiple tests were performed to screen for the existence of a relationship between genetic

270 and demographic data, we applied a q-value correction for multiple tests using the QVALUE software

271 (Storey, 2004; Storey et al., 2003) within the R 2.9.2 package (The R Development Core Team,

272 2004). The q-values indicate the probability of the null hypothesis being correct despite low p-values.

273 The bootstrap method was chosen as recommended by the authors for a limited number of $p$-values

274 (Storey et al., 2002). 


\section{Results}

Clonal diversity descriptors

The probabilities of obtaining the same multi-locus genotype (MLG) through distinct sexual recombination events were very small (all $p_{\text {sex }}<0.01$ ). I dentical MLGS were therefore considered as pertaining to the same clone. Genotypes differing by only one or two loci did not result in a $p_{\text {sex }}<$ 0.01 after removing the distinct loci. All MLGS were therefore considered to pertain to distinct MLLS.

282 Despite standardized sampling area and size, highly variable levels of clonal richness were observed across the Mediterranean (Table 1), with 5 to 34 multi-locus lineages (MLLS) per meadow revealed in sample sizes of 31 to 40 sampling units, and with $R$ ranging from 0.1 to 0.97 .

The Pareto descriptors of clonal diversity also revealed variable richness and evenness, with the maximum clonal size [quantified as the number of sampling units (SUs) belonging to the same MLL] falling between 1 and 35 , and Pareto $\beta$ ranging from 0.03 to 2.35. The clonal subrange also varied widely, from $12.7 \mathrm{~m}$ to $78 \mathrm{~m}$ in the standardized sampling area of $20 \times 80 \mathrm{~m}$.

Genetic descriptors

291 Allelic richness in Spanish meadows, standardized to the maximum common sampling size observed $292(\mathrm{~N}=31)$ using a sub-sampling approach, varied from 2.6 to 5 alleles per locus. Allelic richness was somewhat higher ( 4 to 7 alleles per locus) in the Central (Sicily) and Eastern (Greece and Cyprus)

294 parts of the Mediterranean.

295 Expected and observed heterozygosity ranged from 0.4 to 0.6 and from 0.4 to 1 , respectively. This discrepancy resulted in 13 of the 30 meadows significantly departing from Hardy Weinberg

297 equilibrium, with negative $F_{\text {is }}$ in 12 samples. Heterozygote excesses reached -1 in a meadow off of 298 Cabrera Island (Sa Paret) dominated by a very large heterozygous clone, even though clonal replicates were not included in this estimation.

\section{Shoot demography}

302 The density of meadows also varied immensely, by almost two orders of magnitude (Table 1), mostly

303 due to very low density at impacted aquaculture stations and to depth differences, ranging from 20 
304 shoots per $\mathrm{m}^{2}$ in the deep and heavily impacted station of El Campello to 1550 shoots per $\mathrm{m}^{2}$ in the 305 shallower meadow of Fanals, along the Spanish mainland coast. Specific shoot mortality rates ranged 306 between 0.02 and 0.28 shoot per year in meadows unaffected by aquaculture operations, compared 307 to 0.19 to 1.5 shoot per year at those impacted by fish farm effluents. Low recruitment ( 0.00 to 0.18 308 shoot per year) was unable to balance the high mortality rate in most meadows (28 of the 30 meadows studied). This resulted in declining densities (i.e., declining population growth) at rates of 310 up to -0.25 shoot per year when unaffected by fish farm effluents (in a deep meadow, Sa Paret, 311 Cabrera Island, dominated by a very large clone) and up to -1.39 shoots per year when impacted by 312 fish farming activity (Greek impacted meadow).

313

\section{Sedimentation rates}

Ranges of levels of organic matter, $\mathrm{N}$ and $\mathrm{P}$ and total benthic sedimentation rates, estimated in grams of dry weight. $\mathrm{m}^{2}$.day ${ }^{-1}$, were $0.44-3.80,0.01-0.11,0.01-0.08$ and $5.3-8.94$, respectively, at stations located near aquaculture cages (Table 2). Except for total organic matter at Fanals (Table 2), lower values were observed in control stations and in other meadows sampled along the Spanish coasts, which had ranges of $1.59-11.54$ for total sedimentation, $0.42-2.09$ for organic matter and 0.01-0.06 for nitrogen and a noticeably lower range of values for phosphorus (0.00-0.01).

Tests for correlations

323 There was a significant, positive relationship (Table 3) between mortality rates and genotypic evenness (Pareto beta: $r^{2}=0.54, p<0.01$, $q$-value $=0.00$ ) across all populations, along with negative relationships between net Population growth and clonal richness and clonal evenness (Pareto beta: $r^{2}=0.51, p=0.00, q$-value $\left.=0.00\right)$ and allelic richness $\left(\hat{A}: r^{2}=0.20, p=0.04, q\right.$-value $\left.=0.47\right)$, although the latter q-values (significance corrected for multiple tests) reflect a non-negligible probability of type I error. In any case, the significance of any of these relationships was entirely dependent on the high evenness and allelic richness in the four meadows highly impacted by fish cages, and no relationship was evident when these populations were excluded. No other correlation was observed between any of the other clonal or genetic versus demographic parameters. 
333 Mortality rates were generally positively related to sedimentation rates as represented by inputs of 334 organic matter and nitrogen when the heavily impacted meadows were excluded (Table 4). When all 335 meadows were included, this positive relationship was significant for phosphorous. The q-values 336 ranged from 0.00 to 0.03 for all $p$-values below 0.09 , indicating that a low $p$-value could be reliably 337 interpreted as significant.

338

339 No significant relationship ( $p>0.05$ ) was found between the residuals of these mortality vs. pressure 340 (i.e., sedimentation rate) regressions (which represent the extent of mortality for any given additional 341 pressure) and clonal or genetic diversity parameters.

342

343

344 
Discussion

Global patterns of genetic diversity versus demographic status of seagrass meadows

349 This study reveals that in Posidonia oceanica meadows, less clonal (more genotypically diverse) populations are associated with higher mortality and that populations with more alleles (more genetically diverse) have lower net population growth. This is shown by the positive relationship observed between mortality rate and genotypic diversity (i.e., clonal richness and evenness as estimated with $\mathrm{R}$ and Pareto beta) and the negative relationship between the net rate of population growth and genetic diversity (allelic richness) (Table 3, Figure 1).

This is in contrast with theoretical expectations (Kimura 1983) and with some empirical observations (Spielman et al. 2004) of a positive relationship between population growth or effective size and genotypic or genetic diversity in natural populations. The unexpected relationship is, however, in line with the finding by Hämmerli and Reusch (2003) of a lower number of genets in a Zostera marina meadow under low disturbance in comparison with a highly disturbed one. It also agrees with the empirical results reported for the subset of meadows impacted by aquaculture effluents (Diaz-Almela et al. 2007), which are also included in the present, more extensive, dataset. This previous study revealed lower specific mortality, reflecting higher resistance, in meadows impacted by aquaculture when the meadows initially harbored larger clones and consequently lower clonal diversity. A negative relationship between current genetic or genotypic diversity and population dynamics is confirmed when including 17 additional meadows in the study. In contrast with previous studies, information on the genetic structure of the meadows prior to the impacts assessed here is not available. Accordingly, the relationship between the genetic structure and the demographic dynamics

369 presented here does not allow causal inferences as to whether the genetic structure observed is derived from the demographic dynamics or vice versa. The general negative trends observed may be attributed to several causes. For instance, Diaz-Almela et al. (2007) observed that meadows with low

372 genotypic diversity are more resistant to impacts and suggested that this may be linked to the 373 presence of large, dominant clones that have been selected in the long term for phenotypic plasticity, 
374 thus causing lower genotypic diversity. Low genotypic diversity may also result from competitive

375 exclusion of clonal lineages under mid- or long-term demographic stability, as suggested for species coexistence models (Huston 1979). These models predict that stable environmental conditions may promote out-competition of clonal lineages and consequent reduction of genotypic diversity, whereas environmental fluctuations may promote clonal diversity by reducing the impact of competition. This is in line with the hypothesis of Hämmerli and Reusch (2003) to explain the lower diversity in more stable meadows by greater efficiency of competition resulting in relatively more outbred clones outcompeting more inbred ones under a lower disturbance regime.

Remarkably, no significant relationship between demography and genetic or genotypic diversity remains when meadows heavily impacted by fish farm effluents are excluded from the analysis, suggesting that such a global relationship emerges only beyond a critical mortality threshold. Although the genotypic and genetic variability observed in the meadows result from the total demographic history of the meadows, likely spanning across millennia, the estimated demographic rates derived here reflect short-term, annual estimates that may depend on current environmental pressures rather than on the history of the meadows. It seems that the global relationship observed here may be driven mostly by those meadows that have experienced extreme disturbance imposed by inputs of aquaculture effluents that have significantly altered the genotypic and genetic diversity of the meadows (Diaz-Almela et al. 2007). The lack of relationship observed when removing the outliers corresponding to highly impacted meadows is consistent with the results reported by Reusch (2006), who found no significant pattern in genotypic diversity across a gradient of moderate disturbance in natural Z. marina meadows.

Further support for the weakness of this relationship comes from the analysis of the sedimentation inputs, which shows a rather tight relationship with shoot mortality in Posidonia oceanica across the Mediterranean, both when including highly impacted meadows and when excluding these (Table 3). This confirms the notion that $P$. oceanica meadows are strongly vulnerable to inputs of organic materials and nutrients to the sediments (Marbà et al. 1996, Marbà et al. 2005, Diaz-Almela et al. 2008). The relationship between shoot mortality and sedimentation inputs explains so much variance 
$403(96 \%)$ in $P$. oceanica mortality rates that any effect of genetic diversity must necessarily be small, as

404 the residual error is already close to the uncertainty of mortality estimates. Indeed, no significant 405 relationship is observed between the residuals of the relationship between mortality and 406 sedimentation rate and genotypic or genetic diversity descriptors of the studied meadows.

408 The comparative analyses presented here highlight the challenges of detecting relationships between 409 demography and genetic traits in the presence of other sources of variance, including differential 410 environmental pressures. In order to resolve the influence of genetic composition on the ability of 411 populations to respond to environmental stress, in situ observation requires the availability of pre412 disturbance genotypic and genetic parameters, which are seldom available because most studies on 413 declining populations are initiated in response to observed demographic decline. One alternative is to 414 estimate these parameters in non-impacted areas belonging to the same meadow, as reported 415 previously (Diaz-Almela et al. 2007); another is to design experimental manipulations controlling initial 416 genotypic and/or genetic parameters and environmental variability. Such experiments, focused on the role of Zostera marina genotypic diversity in responses to disturbances, have been conducted in the 418 field by Hughes and Stachowicz (2004) and Reusch et al. (2005) and in laboratory conditions by 419 Ehlers et al. (2008).

420 These experimental studies have revealed the positive influence of genotypic (i.e., clonal) diversity on 421 the ability of experimental populations of Zostera marina to successfully overcome major 422 environmental stresses, such as massive grazing (Hughes \& Stachowicz 2004) and an exceptional heat 423 wave (Reusch et al. 2005, Ehlers et al. 2008). Yet, in situ comparative analyses of genetic structure 424 under heavy mortality induced by fish farm effluents has revealed better performance of Posidonia 425 oceanica meadows bearing larger clones and lower allelic diversity before the impact (where the 426 genetic structure at the control stations was used as a proxy for the genetic structure near the cages 427 before the impact: Diaz-Almela et al. 2007). This finding implies that populations with low genotypic 428 and genetic diversity are more resistant to disturbance, a process likely to result from the fitness 429 advantages of individuals with large clonal sizes (Diaz-Almela et al. 2007). This discrepancy in 430 inferred roles of genotypic and genetic diversity in population stability in small scale experiments 
versus larger scale in situ observations raises the question of which spatial and temporal scales are 432 captured in both kinds of studies.

Experimental manipulations at small spatial and temporal scales may not capture the 434 complexity of the genetic structure of natural seagrass meadows, shaped across millennia. Both Zostera marina and Posidonia oceanica populations exhibit strong dominance by large clones with tens of thousands of shoots each, reflected in a Pareto distribution of clonal sizes typical of those observed 437 in most clonal organisms tested to date (Arnaud-Haond et al. 2007a) that exhibit millenary life spans, 438 as suggested in some locations for both $Z$. marina (Reusch et al. 1999) and P. oceanica (ArnaudHaond et al. submitted). The genetic structure of natural populations is therefore strikingly different 440 from the even composition of experimental plots, which are typically designed with an equal number 441 of ramets for each of the represented genotypes, with rhizome connections broken to make small 442 clusters of not more than three (Hughes \& Stachowicz 2004) to six (Reusch et al. 2005) connected 443 shoots. These are very small clones compared to those found in natural populations. At small spatial 444 and temporal scales, genotypic richness in synthetic experimental plots may confer greater resistance 445 to sudden imposed disturbances. At larger scales, the presence of large clones, which results in 446 reduced genotypic diversity, may increase resistance to disturbances due to i) their higher fitness, 447 possibly selected for through long periods of time by selective processes related to their ability to 448 outcompete relatively less fit clonal lineages and to cope with environmental fluctuations occurring 449 over large periods of time and ii) their ability to integrate resources and impacts in a possibly 450 heterogeneous landscape.

In order to understand these discrepancies and test for possible effects of plasticity selected 452 over centuries or clonal integration associated with large size, different kinds of experiments and in 453 situ observations may be planned in the future. The effect of clonal integration may be tested for by 454 designing plots bearing the same genotypes, but with series of interconnected shoots of different 455 sizes. Better performance of plots with more interconnected shoots would reveal a positive effect of 456 integration potential. As for the possible enhanced phenotypic plasticity of clones selected over 457 decades or centuries in natural meadows, experiments have been designed to date with a selection of 458 the largest clones available, as the aim has been to compare individual clonal fitness and many 459 replicates were therefore needed (Hughes \& Stachowicz 2004, Reusch et al. 2005, Ehlers et al. 2008). 
460 In order to test for the putative increased fitness of existing large and old clones, experimental plots 461 bearing comparable assemblages in terms of clonal richness may be designed with clones exhibiting a

462

463

464

465

466

467

468

469

470

471

472

473

474

475

476

477

478

479

480

481

482

483

484

485

486

487

488

very restricted distribution in natural meadows versus clones known to extend across large areas in the field, likely representing the outcome of selective pressure and competition acting over large temporal scales. Such experiments would allow a better understanding of the evolution of genotypes and the importance of genotypic richness in natural populations, which are relevant questions for clonal organisms in general. As an example, most corals, which rank amongst the most threatened habitats in the world, are clonal with physical interconnection of the different clone mates for most species.

(1)

Finally, besides the importance of genotypic richness, a concept specific to clonal organisms that reflects the co-occurrence of distinct clonal lineages in a given population, experiments focused on genetic richness in a broader sense (i.e., genetic richness as estimated by allelic richness and diversity as estimated by, for example, heterozygosity) are needed. Reusch et al. (2005) proposed to decompose the genetic diversity of seagrass into a combination of 'genomic diversity' (i.e., the level of genetic polymorphism) and 'genotypic diversity' (i.e., clonal diversity, the number of genetic individuals or clonal lineages actually present in a set of samples that may include replicates of the same clonal lineages). Genotypic diversity estimates the relative abundance of distinct clonal lineages, reflecting the relative contribution of clonal versus sexual reproduction in a given population. For seagrass meadows, where many shoots of a given clone may be distributed over tens of meters, genotypic diversity reflects only the relative abundance of genetically distinct individuals (originating from distinct events of sexual reproduction). Above a minimum number of clonal lineages, there is no support for the expectation of any relationship between the number of genotypes and the genetic richness or 'diversity' (in the classical population genetics sense) in a given sample of clones (Hughes et al. 2008). Hughes and Stachowicz (2004) specifically state that "to avoid confounding the potential effects of genotypic diversity with those of multilocus heterozygosity on plant performance ..., genotypes were assigned to treatments such that average multilocus heterozygosity did not vary with genotypic richness"; i.e., genomic diversity was set be uniform. However, the difference between genomic and genotypic seagrass diversity has not yet been clarified in the literature discussing such 
studies (e.g., Frankham et al. 2005a). Genotypic diversity may enhance the ability of a particular

clonal population to cope with environmental changes that occur too suddenly to leave time for sexual reproduction to play a role in the immediate response of the population by rearranging the 'genomic 492 diversity' into new clonal lineages. Yet, 'genomic diversity' recovering the existence of different allelic 493 forms of the same genes in a given population, which might perform differently under different environmental conditions, is the component of genetic diversity with the greatest bearing on the 'evolutionary potential' of populations, operating at mid- to long- time scales to buffer them against environmental changes. Indeed, 'genomic diversity' is the concept that most biologists not specifically concerned with clonal organisms identify with the term 'genetic diversity', as 'genotypic diversity' is a 498 concept applicable only to clonal organisms. Therefore, it is important to emphasize that although 499 theory and some empirical observations support the hypothesis of an influence of genetic diversity (in the classical sense of this term, reflecting 'evolutionary potential') on the ability of populations or 501 species to cope with significant environmental changes, this remains to be tested. Future experiments 502 to address this may also focus on allelic richness by designing controlled plots comparable to those designed for clonal organisms for genotypic richness but also manipulating allelic richness and/or

504 heterozygosity, allowing the importance of 'genomic' diversity for the evolutionary potential of both 505 non-clonal and clonal species to be tested.

In summary, the results reported here show that, in contrast to expectations, there is no 507 evidence for a negative relationship between seagrass mortality and genetic diversity in the study 508 area. Indeed, a positive relationship emerges when highly impacted meadows are included. A comparative analysis across Mediterranean Posidonia oceanica meadows experiencing a broad range

510 of disturbance provides no evidence that any component of genetic diversity significantly affects the 511 level of mortality experienced for any given degree of environmental pressure. Although the 512 importance of genetic diversity in seagrass conservation cannot be dismissed, the results available 513 suggest that this influence emerges only against the variance introduced by other factors, in highly 514 simplified, experimental situations or under extreme disturbance.

515 


\section{Acknowledgments}

518 This research was funded by projects M\&MS (EVK3-CT-2000-00044) and MedVeg (Q5RS-2001-02456

519 of FP5), a project funded by the BBVA Foundation, the Portuguese Fundação para a Ciência e a 520 Tecnologia (FCT) and FEDER through project DIVSTAB-(POCI 2010) and a FCT and FSE postdoctoral 521 fellowship (S.A.-H.). 


\section{References}

523

524

525

526

527

528

529

530

531

532

533

534

535

536

537

538

539

540

541

542

543

544

545

546

547

548

549

550

551

552

553

554

555

556

557

558

Alberto F, Correia L, Arnaud-Haond S, Billot C, Duarte CM, Serrão EA (2003) New microsatellites markers for the endemic Mediterranean seagrass Posidonia oceanica. Molecular Ecology Notes 3:253-255

Arnaud-Haond S, Alberto F, Teixeira S, Procaccini G, Serrao EA, Duarte CM (2005) Assessing genetic diversity in clonal organisms: Low diversity or low resolution? Combining power and cost efficiency in selecting markers. J ournal of Heredity 96:434-440

Arnaud-Haond S, Belkhir K (2007) GenClone 1.0: a new program to analyse genetics data on clonal organisms. Molecular Ecology Notes 7:15-17

Arnaud-Haond S, Duarte CM, Alberto F, Serrão EA (2007a) Standardizing methods to address clonality in population studies. Molecular Ecology 16:5115-5139

Arnaud-Haond S, Duarte CM, Diaz-Almela E, Marbá N, Serrao EA (submitted) Extant Pleistocene Clones Detected in a Threatened Seagrass

Arnaud-Haond S, Migliaccio M, Diaz-Almela E, Teixeira S, van de Vliet MS, Alberto F, Procaccini G, Duarte CM, Serrao EA (2007b) Vicariance patterns in the Mediterranean Sea: east-west cleavage and low dispersal in the endemic seagrass Posidonia oceanica. Journal of Biogeography 34:963-976

Belkhir K, Borsa P, Chikhi L, N.Raufaste, Bonhomme F (1996-2001) GENETIX 4.02, logiciel sous Windows TM pour la génétique des populations. Laboratoire Génome et Populations, Interactions, Adaptations, CNRS UMR5000, Université Montpellier II, Montpellier (France)

Blomqvist S, Hakanson L (1981) A review on sediment traps in aquatic environments. Archiv Fur Hydrobiologie 91:101-132

Diaz-Almela E, Arnaud-Haond S, Vliet MS, Alvarez E, Marba N, Duarte CM, Serrao EA (2007) Feedbacks between genetic structure and perturbation-driven decline in seagrass (Posidonia oceanica) meadows. Conservation Genetics 8:1377-1391

Diaz-Almela E, Marba N, Alvarez E, Santiago R, Holmer M, Grau A, Mirto S, Danovaro R, Petrou A, Argyrou M (2008) Benthic input rates predict seagrass (Posidonia oceanica) fish farm-induced decline. Marine Pollution Bulletin 56:1332-1342

Dorken ME, Friedman J, Barrett SCH (2002) The evolution and maintenance of monoecy and dioecy in Sagittaria latifolia (Alismataceae). Evolution 56:31-41

Doyle J J, Doyle J LI (1987) A rapid DNA isolation procedure for small quantities of fresh leaf tissue. Phytochemistry Bulletin 11:11-15

Ehlers A, Worm B, Reusch TBH (2008) Importance of genetic diversity in eelgrass Zostera marina for its resilience to global warming. Marine Ecology-Progress Series 355:1-7

Frederiksen MS, Holmer M, Perez M, Invers, Ruiz JM, Knudsen BB. (2008). Effect of increased sediment sulfide concentrations on the composition of stable sulfur isotopes (delta S-34) and 
sulfur accumulation in the seagrasses Zostera marina and Posidonia oceanica. J ournal of Experimental Marine Biology and Ecology 358: 98-109

Frankel OH (1974) Genetic Conservation: our responsability. Genetics 78:53-56

Frankel OH, Soulé ME (1981) Conservation and Evolution., Vol, Cambridge

Frankham R (1995) Conservation Genetics. Ann Rev Genetics 29:305-327

Frankham R (2005) Genetics and extinction. Biological Conservation 126:131-140

Gacia E, Granata TC, Duarte CM (1999) An approach to measurement of particle flux and sediment retention within seagrass (Posidonia oceanica) meadows. Aquatic Botany 65:255-268

Hämmerli A, Reusch TBH (2003) Inbreeding depression influences genet size distribution in a marine angiosperm. Molecular Ecology 12:619-629

Harada Y, Kawano S, I wasa Y (1997) Probability of clonal identity: inferring the relative success of sexual versus clonal reproduction from spatial genetic patterns. J ournal of Ecology 85:591-600

Hargrave BT, Burns NM (1979) Assessment of sediment trap collection efficiency. Limnology and Oceanography 24:1124-1136

Holmer M, Argyrou M, Dalsgaard T, Danovaro R, Diaz-Almela E, Duarte CM, Frederiksen M, Grau A, Karakassis I, Marba N (2008) Effects of fish farm waste on Posidonia oceanica meadows: Synthesis and provision of monitoring and management tools. Marine Pollution Bulletin 56: $1618-1629$

Hughes AR, Inouye BD, Johnson MT, Underwood N, Vellend M (2008) Ecological consequences of genetic diversity. Ecology Letters 11:609-623

Hughes AR, Stachowicz JJ (2004) Genetic diversity enhances the resistance of a seagrass ecosystem to disturbance. PNAS 101:8998-9002

Huston M (1979) General hypothesis of species-diversity. American Naturalist 113:81-101

Johnson KH, Vogt KA, Clark HJ, Schmitz OJ, Vogt DJ (1996) Biodiversity and the productivity and stability of ecosystems. Trends in Ecology \& Evolution 11:372-377

Kimura M (1983) The Neutral Theory of Molecular Evolution, Vol, Cambridge

Koroleff F (1983) Determination of nutrients. In: K. Grasshof MEaKK (ed) Methods of seawater analysis. Verlag Chemie, Weinheim, New York., p 125-139

Lande R (1995) Mutation and Conservation. Conservation Biology 9:782-791

Loreau M, Naeem S, Inchausti P, Bengtsson J, Grime JP, Hector A, Hooper DU, Huston MA, Raffaelli D, Schmid B, Tilman D, Wardle DA (2001) Ecology - Biodiversity and ecosystem functioning: Current knowledge and future challenges. Science 294:804-808

Lynch M, Conery J, Burger R (1995) Mutational meltdowns in sexual populations. Evolution 49:10671080

Marbà N, Duarte CM, Cebrian J, Gallegos ME, Olesen B, SandJ ensen K (1996) Growth and population dynamics of Posidonia oceanica on the Spanish Mediterranean coast: Elucidating seagrass decline. Marine Ecology-Progress Series 137:203-213 
Marbà N, Duarte CM, Diaz-Almela E, Terrados J, Alvarez E, Martiinez R, Santiago R, Gacia E, Grau AM (2005) Direct evidence of imbalanced seagrass (Posidonia oceanica) shoot population dynamics in the Spanish Mediterranean. Estuaries 28:53-62

Mascaro O, Valdemarsen T, Holmer M, Perez M, Romero J (2009). Experimental manipulation of sediment organic content and water column aeration reduces Zostera marina (eelgrass) growth and survival. J ournal of Experimental Marine Biology and Ecology, 373: 26-34

McCann KS (2000) The diversity-stability debate. Nature 405:228-233

Naeem S, Li SB (1997) Biodiversity enhances ecosystem reliability. Nature 390:507-509

Newman D, Pilson D (1997) Increased probability of extinction due to decreased genetic effective population size: Experimental populations of Clarkia pulchella. Evolution 51:354-362

Orth RJ , Carruthers TJ B, Dennison WC, Duarte CM, Fourqurean JW, Heck KL, Hughes AR, Kendrick GA, Kenworthy WJ, Olyarnik S, Short FT, Waycott M, Williams SL (2006) A global crisis for seagrass ecosystems. Bioscience 56:987-996

Parks JC, Werth CR (1993) A Study of Spatial Features of Clones in a Population of Bracken Fern, Pteridium-Aquilinum (Dennstaedtiaceae). American J ournal of Botany 80:537-544

Pfisterer AB, Schmid B (2002) Diversity-dependent production can decrease the stability of ecosystem functioning. Nature 416:84-86

Procaccini G, Piazzi L (2001) Genetic polymorphism and transplantation success in the mediterranean seagrass Posidonia oceanica. Restoration Ecology 9:332-338

Reusch TBH (2006) Does disturbance enhance genotypic diversity in clonal organisms? A field test in the marine angiosperm Zostera marina. Molecular Ecology 15:277-286

Reusch TBH, Bostrom C, Stam WT, Olsen JL (1999) An ancient eelgrass clone in the Baltic. Marine Ecology-Progress Series 183:301-304

Reusch TBH, Ehlers A, Hammerli A, Worm B (2005) Ecosystem recovery after climatic extremes enhanced by genotypic diversity. PNAS 102:2826-2831

Saccheri I, Kuussaari M, Kankare M, Vikman P, Fortelius W, Hanski I (1998) Inbreeding and extinction in a butterfly metapopulation. Nature 392:491-494

Spielman D, Brook BW, Frankham R (2004) Most species are not driven to extinction before genetic factors impact them. Proceedings of the National Academy of Sciences of the United States of America 101:15261-15264

Storey JD, Taylor JE, Siegmund D (2004) Strong control, conservative point estimation and simultaneous conservative consistency of false discovery rates: a unified approach. J ournal of the Royal Statistical Society Series B-Statistical Methodology 66:187-205

Storey JD, Tibshirani R (2003) Statistical significance for genomewide studies. Proceedings of the National Academy of Sciences of the United States of America 100:9440-9445

The R Development Core Team (2004) R: a language and environment for statistical computing R Foundation for Statistical Computing, Vienna, Austria. ISBN 3-900051-00-3, URL http://www.r-project.org/ 
634 Tibayrenc M, Kjellberg F, Ayala F (1990) A Clonal Theory of Parasitic Protozoa: The Population Structures of Entamoeba, Giardia, Leishmania, Naegleria, Plasmodium, Trichomonas, and Trypanosoma and their Medical and Taxonomical Consequences. PNAS 87:2414-2418 Worm B, Barbier EB, Beaumont N, Duffy JE, Folke C, Halpern BS, J ackson JBC, Lotze HK, Micheli F, Palumbi SR, Sala E, Selkoe KA, Stachowicz JJ, Watson R (2006) Impacts of biodiversity loss on ocean ecosystem services. Science 314:787-790

640 Young AG, Hill JH, Murray BG, Peakall R (2002) Breeding system, genetic diversity and clonal structure 641 in the sub-alpine forb Rutidosis leiolepis F. Muell. (Asteraceae). Biological Conservation 642 106: 71-78

643

644 
Table 1: Sampling locations (country, location, GPS coordinates) and number of sampling units collected and analyzed ( $\mathrm{N}_{\mathrm{su}}$ ). For each location, the clonal

\begin{tabular}{|c|c|c|c|c|c|c|c|c|c|c|c|c|c|c|c|c|c|}
\hline & \multicolumn{5}{|l|}{ Sampling data } & \multicolumn{4}{|c|}{ Genotypic data } & \multicolumn{4}{|c|}{$\begin{array}{l}\text { Genetic } \\
\text { data }\end{array}$} & \multicolumn{4}{|c|}{ Demographic data } \\
\hline & Locality & GPS coordina & tes & $\mathrm{N}_{\mathrm{SU}}$ & $\mathrm{N}_{\mathrm{MLL}}$ & $\mathrm{R}$ & $\begin{array}{l}\text { Pareto } \\
\text { beta }\end{array}$ & $\max$ & $\mathrm{CR}$ & $\hat{A}$ & $\mathrm{Hnb}$ & $\begin{array}{l}\text { Hob } \\
\mathrm{s}\end{array}$ & $F_{\text {IS }}$ & $\begin{array}{l}\text { Density } \\
\text { (shoots } \\
. \mathrm{m}^{-2)}\end{array}$ & $\begin{array}{l}\text { RMR } \\
\text { (shoot } \\
\left.. \mathrm{yr}^{-1}\right)\end{array}$ & $\begin{array}{l}\text { RRR } \\
\text { (shoot } \\
. \mathrm{yr}^{-1} \text { ) }\end{array}$ & $\begin{array}{l}\text { NPG } \\
\text { (shoot } \\
\text {.yr-1) }\end{array}$ \\
\hline \multirow[t]{14}{*}{$\begin{array}{l}\text { SPAIN } \\
\text { (peninsula) }\end{array}$} & & & & & & & & & & & & & & & & & \\
\hline & Roquetas & $36^{\circ} 43.26^{\prime} \mathrm{N}$ & $2^{\circ} 37.09^{\prime} \mathrm{W}$ & 40 & 26 & 0.64 & 1.08 & 6 & 47.76 & 3.72 & 0.56 & 0.66 & -0.18 & 425 & & & \\
\hline & Rodalquilar & $36^{\circ} 51.21^{\prime} \mathrm{N}$ & $2^{\circ} 00.53 \mathrm{~W}$ & 40 & 21 & 0.51 & 0.65 & 10 & 44.92 & 4.43 & 0.58 & 0.65 & -0.12 & 966 & & & \\
\hline & Campomanes & $38^{\circ} 37.54^{\prime} \mathrm{N}$ & $0^{\circ} 0.577^{\prime} \mathrm{E}$ & 31 & 22 & 0.70 & 0.76 & 7 & 48.00 & 4.43 & 0.58 & 0.64 & -0.09 & 427 & 0.28 & 0.06 & -0.23 \\
\hline & Torre de la Sal & $40^{\circ} 8.13^{\prime} \mathrm{N}$ & $0^{\circ} 10.72 ' \mathrm{E}$ & 39 & 20 & 0.50 & 0.35 & 7 & 52.92 & 3.57 & 0.51 & 0.55 & -0.08 & 350 & 0.21 & 0.05 & -0.16 \\
\hline & El Arenal & $38^{\circ} 38.37^{\prime} \mathrm{N}$ & $0^{\circ} 3.06^{\prime} \mathrm{E}$ & 39 & 32 & 0.82 & 1.25 & 4 & 31.98 & 4.43 & 0.54 & 0.56 & -0.04 & 431 & 0.24 & 0.15 & -0.09 \\
\hline & El Campelo impacted & $38^{\circ} 25.30^{\prime} \mathrm{N}$ & $0^{\circ} 20.83^{\prime} \mathrm{E}$ & 39 & 26 & 0.66 & 0.93 & 6 & 70.90 & 2.86 & 0.40 & 0.51 & -0.27 & 20 & 0.55 & 0.11 & -0.05 \\
\hline & El Campelo control & $38^{\circ} 24.88^{\prime} \mathrm{N}$ & $0^{\circ} 21.14$ 'E & 40 & 23 & 0.56 & 0.94 & 6 & 68.70 & 4.00 & 0.57 & 0.71 & -0.24 & 68 & 0.06 & 0.11 & 0.05 \\
\hline & La Fossa & $38^{\circ} 33.59^{\prime} \mathrm{N}$ & $0^{\circ} 4.566^{\prime} \mathrm{E}$ & 40 & 31 & 0.77 & 0.97 & 5 & 68.73 & 4.43 & 0.54 & 0.49 & 0.09 & 1551 & 0.24 & 0.03 & -0.19 \\
\hline & Fanals & $41^{\circ} 41,58^{\prime} \mathrm{N}$ & $2^{\circ} 50.56^{\prime} \mathrm{E}$ & 38 & 26 & 0.68 & 0.45 & 11 & 53.45 & 3.71 & 0.48 & 0.58 & -0.21 & 121 & 0.14 & 0.02 & -0.12 \\
\hline & Cala Giverola & $41^{\circ} 44.15^{\prime} \mathrm{N}$ & $2^{\circ} 57.37^{\prime} \mathrm{E}$ & 38 & 17 & 0.43 & 0.23 & 19 & 61.09 & 3.00 & 0.39 & 0.43 & -0.12 & 326 & 0.17 & 0.09 & -0.08 \\
\hline & Cala Jonquet & $42^{\circ} 18,19^{\prime} \mathrm{N}$ & $3^{\circ} 17.36^{\prime} \mathrm{E}$ & 39 & 20 & 0.50 & 0.56 & 9 & 38.33 & 4.14 & 0.53 & 0.51 & 0.05 & 207 & 0.28 & 0.07 & -0.21 \\
\hline & Port Lligat & $42^{\circ} 17,61^{\prime} \mathrm{N}$ & $3^{\circ} 17.58^{\prime} \mathrm{E}$ & 40 & 12 & 0.28 & 0.25 & 17 & 67.07 & 3.29 & 0.54 & 0.67 & -0.25 & 192 & 0.23 & 0.18 & -0.05 \\
\hline & Xilxes & $39^{\circ} 45,13^{\prime} \mathrm{N}$ & $0^{\circ} 8.07{ }^{\prime} \mathrm{E}$ & 32 & 12 & 0.36 & 0.49 & 9 & & 3.14 & 0.51 & 0.67 & -0.13 & & 0.16 & 0.14 & 0.30 \\
\hline
\end{tabular}


Table 1 (continued):

\begin{tabular}{|c|c|c|c|c|c|c|c|c|c|c|c|c|c|c|c|c|c|}
\hline & \multicolumn{5}{|l|}{ Sampling data } & \multicolumn{4}{|c|}{ Genotypic data } & \multicolumn{4}{|c|}{$\begin{array}{l}\text { Genetic } \\
\text { data }\end{array}$} & \multicolumn{4}{|c|}{ Demographic data } \\
\hline & Locality & GPS coordir & ates & $\mathrm{N}_{\mathrm{SU}}$ & $\overline{\mathrm{N}_{\mathrm{MLL}}}$ & $\mathrm{R}$ & $\begin{array}{l}\text { Pareto } \\
\text { beta }\end{array}$ & $\max$ & $\mathrm{CR}$ & $\hat{\mathrm{A}}$ & $\mathrm{H}_{\mathrm{nb}}$ & $\mathrm{H}_{\mathrm{obs}}$ & $F_{\text {IS }}$ & $\begin{array}{l}\text { Density } \\
\text { (shoots } \\
. \mathrm{m}^{-2)}\end{array}$ & $\begin{array}{l}\text { RMR } \\
\text { (shoot } \\
\text {.yr-1) }\end{array}$ & $\begin{array}{l}\text { RRR } \\
\text { (shoot. } \\
\mathrm{yr}^{-1} \text { ) }\end{array}$ & $\begin{array}{l}\text { NPG } \\
\text { (shoot. } \\
\text { yr-1) }\end{array}$ \\
\hline \multirow{5}{*}{$\begin{array}{l}\text { SPAIN } \\
\text { (balears) } \\
\text { Formentera }\end{array}$} & & & & & & & & & & & & & & & & & \\
\hline & Es Caló des Oli & $38^{\circ} 43.49^{\prime} \mathrm{N}$ & 1024.16'E & 40 & 15 & 0.36 & 0.45 & 11 & 46.04 & 5.00 & 0.61 & 0.56 & 0.07 & 403 & & & \\
\hline & Cala Torreta & $38^{\circ} 47.45^{\prime} \mathrm{N}$ & $1^{\circ} 25.18^{\prime} \mathrm{E}$ & 40 & 21 & 0.51 & 0.62 & 10 & 59.20 & 4.29 & 0.54 & 0.52 & 0.04 & 527 & 0.12 & 0.03 & -0.10 \\
\hline & Ses Illetes & $38^{\circ} 45.37^{\prime} \mathrm{N}$ & $1^{\circ} 25.83^{\prime} \mathrm{E}$ & 36 & 22 & 0.60 & 0.50 & 10 & 35.11 & 4.29 & 0.54 & 0.64 & -0.18 & 667 & 0.02 & 0.03 & 0.01 \\
\hline & Es Pujols & $38^{\circ} 43.74^{\prime} \mathrm{N}$ & $1^{\circ} 27.27^{\prime} \mathrm{E}$ & 40 & 27 & 0.67 & 0.88 & 11 & 72.53 & 4.29 & 0.51 & 0.47 & 0.08 & 746 & 0.04 & 0.02 & -0.02 \\
\hline \multirow[t]{4}{*}{ Cabrera } & Es Castel $5 \mathrm{~m}$ & $39^{\circ} 9.16^{\prime} \mathrm{N}$ & $2^{\circ} 55.83^{\prime} \mathrm{E}$ & 40 & 5 & 0.10 & 0.05 & 33 & 73.25 & 2.71 & 0.53 & 0.61 & -0.17 & 704 & 0.11 & 0.04 & -0.06 \\
\hline & Sa Paret $(18 m)$ & $39^{\circ} 8.81^{\prime} \mathrm{N}$ & $2^{\circ} 55.86^{\prime} \mathrm{E}$ & 40 & 5 & 0.10 & 0.03 & 35 & 78.06 & 2.57 & 0.60 & 1.00 & -0.83 & 259 & 0.28 & 0.05 & -0.25 \\
\hline & Cala Sta. María 13m & $39^{\circ} 9.07^{\prime} \mathrm{N}$ & 2056.92'E & 35 & 20 & 0.56 & 0.85 & 7 & 52.96 & 3.14 & 0.51 & 0.53 & -0.04 & 762 & 0.21 & 0.02 & -0.19 \\
\hline & Cala Sta. María 7m & $39^{\circ} 9.00^{\prime} \mathrm{N}$ & $2^{\circ} 56.96$ 'E & 40 & 22 & 0.54 & 0.75 & 8 & 43.78 & 3.72 & 0.42 & 0.47 & -0.11 & 1000 & 0.18 & 0.03 & -0.15 \\
\hline \multirow[t]{2}{*}{ Mallorca } & Magalluf & $39^{\circ} 30.25^{\prime} \mathrm{N}$ & $2^{\circ} 32.59^{\prime} \mathrm{E}$ & 38 & 26 & 0.68 & 1.18 & 5 & 34.79 & 4.29 & 0.56 & 0.52 & 0.07 & 563 & 0.12 & 0.04 & -0.08 \\
\hline & Porto Colom & $39^{\circ} 25.05^{\prime} \mathrm{N}$ & $3^{\circ} 16.18 ' \mathrm{E}$ & 35 & 16 & 0.44 & 0.40 & 12 & 56.68 & 3.72 & 0.57 & 0.78 & -0.38 & 415 & 0.17 & 0.06 & -0.11 \\
\hline \multirow[t]{2}{*}{ Menorca } & Cala Fornells & $40^{\circ} 03.39^{\prime} \mathrm{N}$ & $4^{\circ} 08.26^{\prime} \mathrm{E}$ & 40 & 5 & 0.10 & 0.04 & 34 & 68.41 & 2.57 & 0.46 & 0.40 & 0.15 & 935 & & & \\
\hline & Addaia & $40^{\circ} 00.97^{\prime} \mathrm{N}$ & $4^{\circ} 12.42^{\prime} \mathrm{E}$ & 37 & 25 & 0.67 & 1.06 & 5 & 50.59 & 3.42 & 0.56 & 0.61 & -0.08 & 1090 & & & \\
\hline \multirow[t]{3}{*}{ ITALY( Sicily) } & & & & & & & & & & & & & & & & & \\
\hline & Porto Palo impacted & $36^{\circ} 42.71^{\prime} \mathrm{N}$ & $15^{\circ} 8.44^{\prime} \mathrm{E}$ & 40 & 31 & 0.77 & 1.48 & 4 & 60.50 & 5.42 & 0.63 & 0.59 & 0.06 & 156 & 1.18 & 0.00 & -1.18 \\
\hline & Porto Palo control & $36^{\circ} 43.31^{\prime} \mathrm{N}$ & $15^{\circ} 8.48^{\prime} \mathrm{E}$ & 40 & 29 & 0.72 & 0.84 & 5 & 41.68 & 5.71 & 0.61 & 0.64 & -0.04 & 395 & 0.28 & 0.03 & -0.25 \\
\hline \multirow{2}{*}{ GREECE } & Sounion impacted & $37^{\circ} 39.59^{\prime} \mathrm{N}$ & $23^{\circ} 57.29^{\prime} \mathrm{E}$ & 37 & 34 & 0.92 & 2.35 & 3 & 29.90 & 6.00 & 0.51 & 0.52 & -0.01 & 165 & 1.50 & 0.11 & -1.39 \\
\hline & Sounion control & $37^{\circ} 39.55^{\prime} \mathrm{N}$ & $23^{\circ} 58.24^{\prime} \mathrm{E}$ & 33 & 29 & 0.97 & 2.00 & 1 & 12.70 & 7.00 & 0.57 & 0.58 & -0.02 & 372 & 0.07 & 0.06 & -0.01 \\
\hline \multirow{2}{*}{ CYPRUS } & pacted & $34^{\circ} 41.96^{\prime} \mathrm{N}$ & $33^{\circ} 12.00^{\prime} \mathrm{E}$ & 40 & 18 & 0.44 & 0.28 & 10 & 76.56 & 4.14 & 0.51 & 0.58 & -0.14 & 454 & 0.19 & 0.16 & -0.03 \\
\hline & Amathous control & $34^{\circ} 42.02^{\prime} \mathrm{N}$ & $33^{\circ} 12.99^{\prime} \mathrm{E}$ & 40 & 25 & 0.62 & 0.65 & 9 & 65.10 & 4.57 & 0.47 & 0.46 & 0.01 & 491 & 0.19 & 0.16 & -0.03 \\
\hline
\end{tabular}


655 Table 2: Demographic and sedimentation data for 13 meadows sampled across the Mediterranean.

656 Demographic data are detailed as Density in shoots. $\mathrm{m}^{-2}$, and as Relative Mortality Rate (RMR) , in

657 shoots. $\mathrm{rr}^{-1}$. Total Sedimentation (Sed. Tot.) and the sedimentation of Organic Matter (Sed. OM), of

658 Nitrogen (Sed. N) and of Phosphorus (Sed. P) are indicated in (dry weight: g. $\mathrm{m}^{2}$.day ${ }^{-1}$ ).

\begin{tabular}{|c|c|c|c|c|c|c|c|}
\hline \multirow{3}{*}{ Sampling locations } & \multirow{3}{*}{$\begin{array}{l}\text { Demography } \\
\text { Density } \\
\end{array}$} & \multirow{2}{*}{\multicolumn{5}{|c|}{ Sedimentation }} & \multirow{3}{*}{$\begin{array}{c}\text { Residuals } \\
\text { Mort. Vs } \\
\text { Sed. }\end{array}$} \\
\hline & & & & & & & \\
\hline & & RMR & Sed. Tot. & Sed. OM & Sed. N & Sed P. & \\
\hline Porto Palo impacted & 156 & 1.18 & 8.94 & 3.80 & 0.11 & 0.08 & 0.03 \\
\hline Porto Palo control & 395 & 0.28 & 7.00 & 2.35 & 0.04 & 0.01 & 0.26 \\
\hline Amathous impacted & 454 & 0.19 & 6.98 & 1.12 & 0.01 & 0.01 & -0.07 \\
\hline Amathous control & 491 & 0.19 & 4.30 & 1.71 & 0.02 & 0.01 & 0.16 \\
\hline Sounion impacted & 165 & 1.50 & 5.30 & 0.44 & 0.05 & 0.05 & 0.20 \\
\hline Sounion control & 372 & 0.07 & 1.59 & 0.42 & 0.02 & 0.00 & -0.27 \\
\hline El Campelo impacted & 20 & 0.55 & 8.55 & 3.35 & 0.09 & 0.06 & -0.23 \\
\hline El Campelo control & 63 & 0.06 & 2.01 & 0.96 & 0.01 & 0.00 & 0.01 \\
\hline Fanals & 121 & 0.14 & 11.54 & 1.96 & 0.04 & 0.01 & -0.11 \\
\hline Magalluf & 563 & 0.12 & 5.06 & 1.26 & 0.01 & 0.00 & -0.03 \\
\hline Porto Colom & 415 & 0.17 & 8.30 & 1.65 & 0.03 & 0.00 & -0.03 \\
\hline Sa Paret $(18 \mathrm{~m})$ & 259 & 0.28 & 9.00 & 2.09 & 0.06 & 0.00 & 0.07 \\
\hline Cala Sta. María 13m & 762 & 0.21 & 2.97 & 0.57 & 0.01 & - & \\
\hline
\end{tabular}

659

660 
661 Table 3: Overall regressions tested for between genotypic ( $R$, Pareto beta, Pareto max, CR) and genetic ( $\left.\hat{\mathrm{A}}, \mathrm{H}_{\mathrm{obs}}, \mathrm{H}_{\mathrm{nb}}, F_{\mathrm{IS}}\right)$ descriptors and demographic parameters (relative mortality rate RMR, relative recruitment rate RRR, and Net Population Growth NPG) as well as residuals of demographic versus

\begin{tabular}{|c|c|c|c|c|c|c|c|c|c|}
\hline \multirow[b]{2}{*}{ Genotypic } & \multirow{2}{*}{$\begin{array}{l}\text { Demographic } \\
\text { data } \\
\text { Genetic data }\end{array}$} & \multicolumn{2}{|c|}{ RMR (shoot.yr ${ }^{-1}$ ) } & \multicolumn{2}{|c|}{ RRR (shoot.yr ${ }^{-1}$ ) } & \multicolumn{2}{|c|}{ NPG (shoot.yr-1) } & \multicolumn{2}{|c|}{$\begin{array}{l}\text { Residuals Multip. } \\
\text { Reg. (Mort. Vs } \\
\text { Sed.) }\end{array}$} \\
\hline & & All data & $\begin{array}{l}\text { without } \\
\text { St.3 }\end{array}$ & All data & $\begin{array}{l}\text { without } \\
\text { St.3 }\end{array}$ & All data & $\begin{array}{l}\text { without } \\
\text { St.3 }\end{array}$ & All data & $\begin{array}{l}\text { without } \\
\text { St.3 }\end{array}$ \\
\hline \multirow[t]{4}{*}{ Clonality } & $\mathrm{R}$ & $\begin{array}{c}0.13 \\
p=0.07\end{array}$ & - & - & - & $\begin{array}{c}0.15 \\
p=0.05\end{array}$ & - & - & - \\
\hline & Pareto max & - & - & - & - & - & - & - & - \\
\hline & Pareto beta & $\begin{array}{c}0.54^{\star} \\
\mathrm{p}=0.00\end{array}$ & - & - & - & $\begin{array}{c}0.50^{*} \\
p=0.00\end{array}$ & - & - & - \\
\hline & $\mathrm{CR}$ & - & - & - & - & - & - & - & - \\
\hline \multirow[t]{4}{*}{ Genetics } & $\hat{A}$ & $\begin{array}{c}0.13 \\
p=0.07\end{array}$ & - & - & - & $\begin{array}{c}0.20 \\
p=0.02\end{array}$ & - & - & - \\
\hline & $\mathrm{H}_{\mathrm{nb}}$ & - & - & - & - & - & - & - & - \\
\hline & $\mathrm{H}_{\mathrm{obs}}$ & - & - & - & - & - & - & - & - \\
\hline & $F_{\mathrm{IS}}$ & - & - & - & - & - & - & - & - \\
\hline
\end{tabular}


667 Table 4: Multiple regressions of Sedimentation (Total Sedimentation: Total; Organic Matter: OM;

668 Nitrogen: N; Phosphorus: P) and Demographic parameters (Relative Mortality Rate RMR and Net 669 Population Growth NPG), when analyzing all available data (All data) as well as when excluding the 670 meadows highly impacted by aquaculture installations (Without impacted). Contributions to the 671 multiple regression are detailed for each of the four sedimentation parameters, and the overall 672 regression coefficients, as well as corresponding p-values, are detailed. Non significant values at $673 \alpha=0.05$ are indicated in grey. Values still significant after correction for multiple tests (ie q-values 674 below 0.05 ) are indicated by asterisks*.

675

676

\begin{tabular}{|c|c|c|c|c|}
\hline \multirow{2}{*}{$\begin{array}{l}\text { Demographic data } \\
\text { Sedimentation }\end{array}$} & \multicolumn{2}{|c|}{ RMR (shoot.yr ${ }^{-1}$ ) } & \multicolumn{2}{|c|}{ NPG (shoot.yr-1) } \\
\hline & \begin{tabular}{|l|} 
All data \\
$( \pm$ SE $)$
\end{tabular} & $\begin{array}{l}\text { Without } \\
\text { impacted } \\
( \pm S E)\end{array}$ & $\begin{array}{l}\text { All data } \\
( \pm \text { SE) }\end{array}$ & $\begin{array}{l}\text { Without } \\
\text { impacted } \\
( \pm S E)\end{array}$ \\
\hline Total & $\begin{array}{c}0.03( \pm 0.03) \\
p=0.32\end{array}$ & $\begin{array}{c}-0.01( \pm \\
0.00) \\
p=0.06^{*}\end{array}$ & $\begin{array}{c}-0.04( \pm \\
0.04) p=0.55\end{array}$ & $\begin{array}{c}0.04( \pm 0.10) \\
p=0.09 *\end{array}$ \\
\hline OM & $\begin{array}{c}-0.29( \pm 0,11) \\
p=0.03^{*}\end{array}$ & $\begin{array}{c}0.12( \pm 0.03) \\
p=0.02^{*}\end{array}$ & $\begin{array}{c}0.36( \pm 0.16) \\
p=0.40\end{array}$ & $\begin{array}{c}-0.07( \pm 0.05) \\
p=0.69\end{array}$ \\
\hline N & $\begin{array}{c}4.72( \pm 5,8) \\
p=0.44\end{array}$ & $\begin{array}{c}2.84( \pm 0.09) \\
p=0.046\end{array}$ & $\begin{array}{c}-7.06( \pm \\
8.61) \\
p=0.06^{*}\end{array}$ & $\begin{array}{c}-4.52( \pm 1.68) \\
p=0.27\end{array}$ \\
\hline$P$ & $\begin{array}{c}15.36( \pm 15,7) \\
p=0.01^{*}\end{array}$ & $\begin{array}{c}5.75( \pm 5.80) \\
p=0.395\end{array}$ & $\begin{array}{c}-12.76( \pm \\
6.95) p=0.44\end{array}$ & $\begin{array}{c}-6.73( \pm 11.29) \\
p=0.07^{*}\end{array}$ \\
\hline Overall $r^{2}$ & $0.88 p=0.00^{*}$ & $\begin{array}{c}0.96 \\
p=0.02^{\star}\end{array}$ & $0.75 p=0.02^{*}$ & $0.91 \mathrm{p}=0.07^{*}$ \\
\hline
\end{tabular}


677 Figure 1: Overall regressions between demography (Relative Mortality and Net Population Growth

678 .shoot.yr-1) and genotypic (richness R and evenness Pareto $\beta$ ) or genetic (allelic richness Â)

679 descriptors.

680

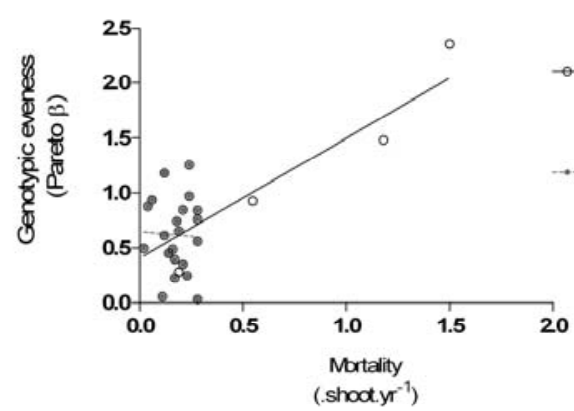

All data

$r^{2}=0,54$
$p<0.0001$

Without aquaculture

Without aqu

stations

$r=0,00$
$p=0,86$

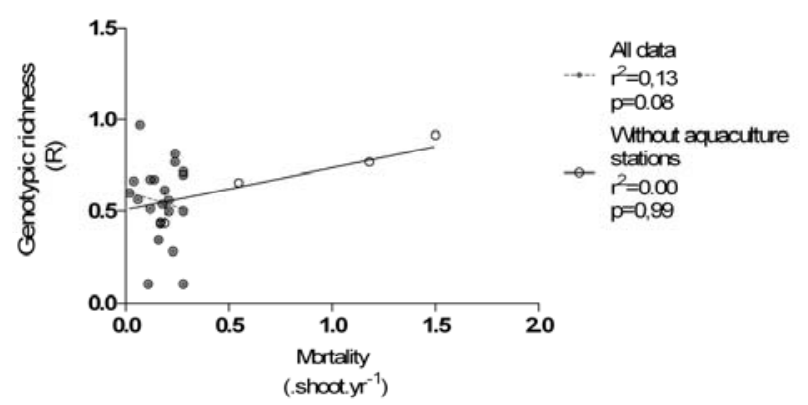

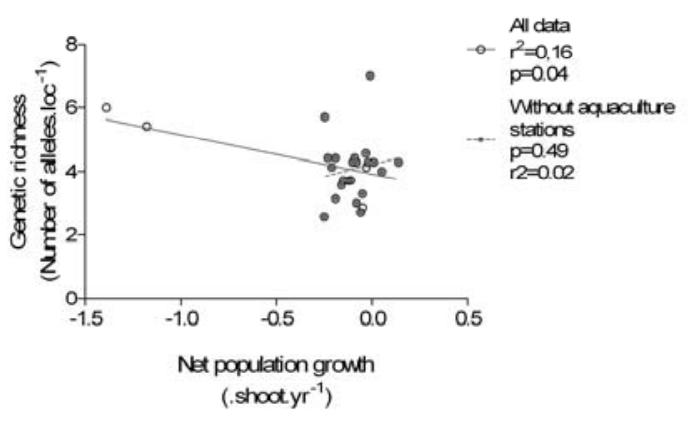

681 